\title{
Folic acid supplementation, preconception body mass index, and preterm delivery: findings from the preconception cohort data in a Chinese rural population
}

Yuanyuan Wang ${ }^{1,2}$, Zongfu Cao ${ }^{1,2}$, Zuoqi Peng ${ }^{1}$, Xiaona Xin ${ }^{1,2}$, Ya Zhang ${ }^{1}$, Ying Yang ${ }^{1}$, Yuan $\mathrm{He}^{1}$, Jihong Xu ${ }^{1}$ and $\mathrm{Xu} \mathrm{Ma}{ }^{1,2^{*}}$

\begin{abstract}
Background: Folic acid (FA) supplementation before and during the first trimester can reduce the risk of occurrence of preterm delivery (PTD). Preconception body mass index (BMI) is also associated with PTD. This study aimed to investigate the combined effect of FA supplements and preconception BMI on the risk of PTD.

Methods: The data of a cohort from 2010-2011 that was obtained through a preconception care service in China was used (including 172,206 women). A multivariable regression model was used to investigate the association between maternal preconception conditions and the risk of PTD. The interaction of preconception BMI and FA supplementation was measured by a logistic regression model.

Results: Taking FA supplements in the preconception period or in the first trimester reduced the risk of PTD (odds ratio $[O R]=0.58$ and $O R=0.61$, respectively). Women with an abnormal $B M l$ had an increased risk of PTD $(O R=1.09$, $\mathrm{OR}=1.10$, and $\mathrm{OR}=1.17$ for underweight, overweight, and obese, respectively). Preconception BMl showed an interaction with the protective effect of FA supplementation for PTD. With regard to the interaction of FA supplementation, the adjusted odds ratio (aOR) was 0.57 (95\% Cl: 0.51, 0.64) in underweight women, 0.85 (95\% Cl: 0.73, 0.98) in overweight women, and $0.77(95 \% \mathrm{Cl}, 0.65,0.91)$ in obese women. Preconception BMl also showed an interaction with the time of FA supplementation. Women with a normal BMI who began to take FA supplements in the preconception period had the lowest risk of PTD (aORs: 0.58 vs. 0.65 beginning in the first trimester). The aORs at preconception and the first trimester in the underweight group were $0.56 \mathrm{vs}$. 0.60 . The aORs at preconception and the first trimester were $0.94 \mathrm{vs}$. 0.65 and 1.15 vs. 0.60 in the overweight and obesity groups, respectively.

Conclusions: In our study, FA supplements reduced the risk of PTD, while abnormal BMI raised the risk of PTD, although higher BMI categories did not have this higher risk once adjusted analysis was conducted. The protective effect of FA supplementation for PTD was reduced in women with overweight or obesity. To get better protection of FA supplementation, women with normal BMI or underweight should begin to use in preconception, while women with overweight or obesity should begin to use after conception.
\end{abstract}

Keywords: Folic acid supplement, Maternal body mass index, Interaction, Preterm deivery, Preconception

\footnotetext{
*Correspondence: genetic88@126.com

${ }^{1}$ National Research Institute for Family Planning, No. 12, Dahuisi Road,

Haidian District, Beijing 100081, China

${ }^{2}$ Graduate School of Peking Union Medical College, No. 9, Dongdansantiao,

Dongcheng District, Beijing 100730, China
}

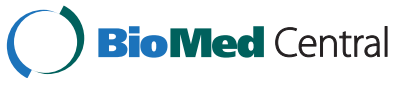

(C) 2015 Wang et al. Open Access This article is distributed under the terms of the Creative Commons Attribution 4.0 International License (http://creativecommons.org/licenses/by/4.0/), which permits unrestricted use, distribution, and reproduction in any medium, provided you give appropriate credit to the original author(s) and the source, provide a link to the Creative Commons license, and indicate if changes were made. The Creative Commons Public Domain Dedication waiver (http://creativecommons.org/publicdomain/zero/1.0/) applies to the data made available in this article, unless otherwise stated. 


\section{Background}

Preterm delivery (PTD) is defined as neonates who are born alive before 37 weeks of pregnancy are completed. PTD is the second largest direct cause of child deaths in children younger than 5 years and causes approximately 1 million deaths annually worldwide. Additionally, PTD causes lifelong problems for many survivors [1].

The incidence of PTD was $7.1 \%$ in a multicenter, hospital-based investigation (based on 107,905 deliveries) in China. The proportion of PTD among the causes of neonatal death has significantly increased from $33.6 \%$ in 2003 to $40.9 \%$ in 2008. PTD is the leading cause of neonatal death in China [2]. Because of the large population in China, China has become the second largest country with annual preterm deliveries. PTD is a serious public health problem in China.

PTD is thought to be a syndrome that is initiated by multiple mechanisms. However, the precise mechanism of PTD has not been established. Therefore, factors associated with preterm birth, but not obviously in the causal pathway, have been sought to explain preterm labor.

Folic acid (FA), an oxidized synthetic water-soluble member of the vitamin-B complex family, plays an essential role in one-carbon metabolism. The clinical application of FA supplementation to prevent neural tube defects (NTD) had been well proven in the last 20-25 years. Pregnant women are at risk of folate deficiency because pregnancy greatly increases folate requirements, especially during periods of rapid fetal growth (i.e., in the second and third trimesters). Although the relation between maternal folate status with NTD has been well established [3, 4], the association of folate status with other adverse pregnancy outcomes is still unclear [5]. Recently, some researchers have investigated maternal FA supplementation and PTD, but the findings were largely inconclusive. Some results supported protective effects [6-9] and some did not [10-14, 15]. A large population-based cohort study conducted in China showed that daily intake of $0.4 \mathrm{mg}$ folic acid reduced the risk of PTD [6]. A cohort in Singapore showed that higher plasma folate concentrations were associated with a longer gestational age and tended to be associated with a lower risk of PTD [16]. Similar results were obtained in some prospective observational studies in the USA $[17,18]$. Some researches have shown that maternal FA supplementation during pregnancy protects against lipopolysaccharideinduced PTD through its anti-inflammatory effects [19-21]. Researchers have hypothesized that lower maternal serum folate concentrations during pregnancy is associated with higher maternal plasma homocysteine concentrations, which cause pre-eclampsia and affect placental function, eventually leading to PTD $[22,23]$.

Abnormal preconception body mass index (BMI) is a risk factor for PTD [24, 25, 26]. The spontaneous PTD rate is higher in pre-pregnancy underweight women
(BMI $<18.5 \mathrm{~kg} / \mathrm{m}^{2}$ ) than in normal-weight women [27, 28]. Some researchers have found that indicated PTD and premature rupture of the membranes are associated with preconception obesity, especially in extremely obese groups $[27,29]$. Obese women are more likely to develop pre-eclampsia and diabetes, and have indicated preterm births associated with these disorders [30]. In a Boston birth cohort, pre-pregnancy obesity was associated with a decreased odds of PTD (0.76) and underweight was nearly associated with an increased odds of PTD (1.46) for spontaneous delivery [30].

Maternal BMI and FA supplementation can affect the risk of PTD. Some studies have shown that there is an inverse interaction between BMI and serum folate levels $[31,32]$. Distribution of folate in the body is significantly affected by obesity, and should pregnancy occur, it may reduce the amount of folate available to the developing embryo [33-35]. The FA supplement guideline in Canada suggests that women with a BMI $>35 \mathrm{~kg} / \mathrm{m}^{2}$ should take 5-mg folate supplements daily to prevent a poor outcome [36].

Whether there is any interactive effect between preconception BMI and FA supplementation for PTD is unclear. These previous studies mentioned above were mostly based on Caucasians, and there is a lack of Chinese population data. In this study, we aimed to determine whether FA supplementation can reduce the risk of PTD in China. We also investigated whether there is an interaction between FA supplementation and maternal BMI for the risk of PTD in the Chinese population.

\section{Methods}

\section{Study design}

This study was designed as a retrospective cohort study. From 2010, the free National Pre-pregnancy Checkups Project (NPCP) for rural women was carried out, which collected the largest pregnancy cohort data from the preconception stage in China. The NPCP is a populationbased, free, preconception medical examination and services for rural reproductive-age couples who are trying to conceive in China. The NPCP covers couples who are preparing for pregnancy, from a preconception examination to pregnancy outcome follow-up. In 2010, the NPCP was first carried out in a 100-district region in China. In this study, examination data of the 100 districts in 2010 was used. The 100 districts are distributed throughout 18 provinces, including four provinces in eastern China (Jiangsu, Zhejiang, Shandong, and Guangdong), six provinces in central China (Hebei, Jilin, Anhui, Henan, Hubei, and Hunan), and eight provinces in western China (Guangxi, Chongqing, Sichuan, Guizhou, Yunnan, Shanxi, Gansu, and Xinjiang). The total population of the research area in 2010 was 7.16 million (females, 3.49 million; males, 3.67 million, approximately $5 \%$ of the total population of 
China [37]). The rural population in the 100 districts was 4.76 million (66 \% of the total population). Rural couples trying to conceive who lived in these areas could receive a free medical checkup in county-level medical institutions from January 2010 to December 2010 in the project. The clinical data were collected during the preconception medical examination. Information on socioeconomic background, reproductive history and history of illness, lifestyle behaviors, and dietary habits were carefully collected through face-to-face interviews by qualified nurses. Physical and biochemical examinations were also carried out by medical staff at the same time, including measurement of maternal height, weight, blood pressure, and hemoglobin levels.

After the examination, the couples received two followup interviews. The first interview was a telephone interview carried out by a trained nurse 3 months after conception. This interview was designed to obtain information of the last menstrual period and FA supplement use status (including the time when first taking FA). The second interview was carried out face-to-face or by telephone 1 month after delivery. Newborn information was collected by a trained interviewer according to the participants' answers. The current study was conducted in accordance with the Declaration of Helsinki (2000) of the World Medical Association and the protocols were approved by the Institutional Research Review Board at the National Population and Family Planning Commission. Informed consent in Chinese was obtained from all NFPC participants.

\section{Study population}

Couples who attended the preconception medical examination and obtained successful conception within 6 months in the cohort were eligible $(200,165)$. A total of 19,398 participants were excluded because of missing data, lost to follow-up, abortion (spontaneous or induced), and stillbirth. Women with post-term pregnancy $(\geq 42$ weeks) and multiple pregnancies were not included in the study (8561). Finally, 172,206 pregnancies were selected for analysis (Fig. 1).

\section{Definition of variables}

The outcome variable in this analysis was PTD, which was defined as neonates who were born alive before 37 weeks of pregnancy were completed. Gestational age was calculated from the last menstrual period and the birth date. The independent variables were those expected to be associated with PTD based on current literature [38], including pertinent health variables (maternal preconception BMI, anemia, diabetes, and hypertension), pregnancy history, health behavior, and demographic variables. Preconception BMI $\left(\mathrm{kg} / \mathrm{m}^{2}\right)$ was calculated using maternal weight and height during the preconception physical examination.
Because the participants in this study were all Chinese women, Chinese BMI classification standards were used in this study to classify different BMI groups. BMI $<18.5$ was considered underweight, BMI $\geq 18.5$ and $<24$ was considered normal, $\mathrm{BMI} \geq 24$ and $<28$ was considered overweight, and BMI $\geq 28$ was considered obese according to the Chinese population standards $[39,40]$.

FA supplementation was based on self-reported use in the first interview. FA supplementation was defined as women who had used supplements and had either taken FA alone or multivitamins (containing FA). FA supplement information was obtained in the first trimester follow-up. Therefore, we divided FA supplementation into three groups according to the time when the participants began to take FA: none, after conception, and preconception. Hypertension was defined as high blood pressure in the preconception examination (SBP $\geq 140 \mathrm{mmHg}$ or $\mathrm{DBP} \geq 90 \mathrm{mmHg}$ ) and self-reported hypertension. Diabetes was defined as self-reported diabetes or blood sugar $\geq 7 \mathrm{mmol} / \mathrm{L}$. Anemia was defined as hemoglobin levels $<110 \mathrm{~g} / \mathrm{L}$ when the participant took the biochemical examination in the preconception service. Preconception dietary habits were defined as risk factors based on the self report, such as "dislike vegetables" and "vegetarian", which indicated "seldom eat meat and eggs". Tobacco use was defined as smoking at least one cigarette per day for at least 1 year in current smokers.

\section{Statistical analysis}

All analyses were generated using SAS software (version 8.2, SAS Institute Inc., North Carolina). The general characteristics of mothers and children based on different categories of maternal preconception BMI and FA supplementation were compared using the chi-squared test and $t$-test. Logistic regression was used to estimate the crude odds ratio (cOR) and the adjusted odds ratio (aOR) with $95 \%$ confidence intervals (CIs) of PTD [41]. Covariates in the multivariable models included demographic factors (maternal age, education level, ethnic group, and career) and preconception risk factors (hypertension, anemia, alcohol use). The time of FA supplement was calculated by setting the dummy variable. The effect of FA supplementation of different weight group was calculated through the contrasts estimated in the model. A significant $p$ value was set at 0.05 .

\section{Results}

The mean age of the participants was $24.98 \pm 3.87$ years and the mean gestational age was $39.14 \pm 1.67$ weeks. The mean BMI was $21.03 \pm 5.39 \mathrm{~kg} / \mathrm{m}^{2}$. A total of 9573 infants were born PTD. 159,635 (92.7 \%) mothers were 21-35 years old, 163,767 mothers were Han ethnic (95.1\%), and 163,423 had at least a junior or higher 


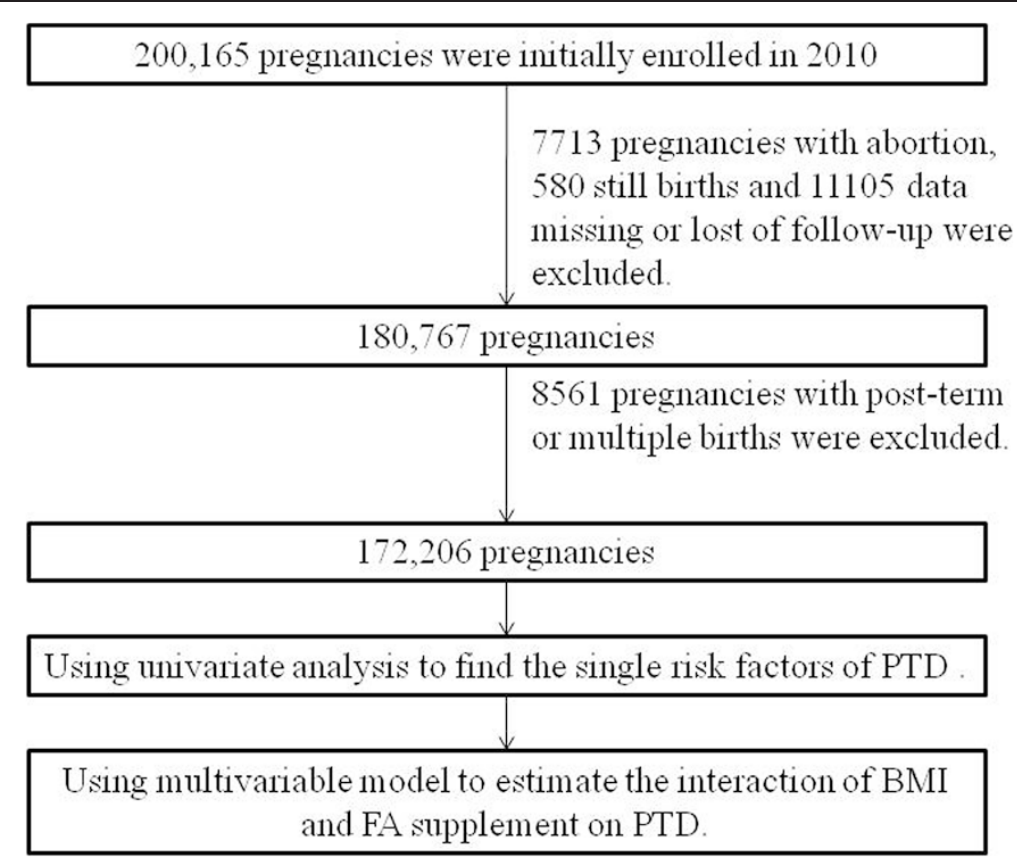

Fig. 1 Flowchart of participant recruitment

school education (94.9\%). The proportion of FA supplementation was $76.8 \%$ and the proportion of an abnormal BMI (obese, overweight, and underweight) was $24.5 \%$. We compared maternal characteristics grouped by preconception BMI and FA supplementation status. Overweight or obese women were more likely to have hypertension or diabetes at preconception than women with a normal BMI or underweight women (Table 1). The proportion of women with high school or higher education experience was higher in women using FA than in nonusers. More population characteristics are shown in Table 1.

Women with an abnormal BMI had an increased risk of PTD $(\mathrm{OR}=1.09$, $\mathrm{OR}=1.10$, and $\mathrm{OR}=1.17$ for underweight, overweight, and obese, respectively). Preconception disease also raised the risk of PTD $(\mathrm{OR}=1.49$ and $\mathrm{OR}=$ 1.19 for hypertension and anemia, respectively). Women using alcohol had a higher risk of PTD $(\mathrm{OR}=1.24)$. The risk of PTD was decreased by taking FA supplements, and this phenomenon was time-related. Taking FA supplements in the preconception period or in the first trimester reduced the risk of PTD $(\mathrm{OR}=0.58$ and $\mathrm{OR}=0.61$, respectively). The difference between the preconception period and the first trimester was not significant by transforming the first trimester as the reference group $(p=0.053)$. Details were listed in Table 2.

An interaction effect was found between preconception BMI and FA supplementation for PTD (Table 3). Taking FA supplements reduced the risk of PTD in all groups. Non-users with a normal BMI had a baseline risk of 7.95
PTD births per 100 live births, whereas mothers who took FA supplements had 4.69 PTD births per 100 live births $(\mathrm{OR}=0.60)$. The OR of FA supplementation varied in different BMI groups. In underweight group, the OR of FA was 0.57 (95\% CI: 0.51, 0.64); in overweight group, the OR was 0.85 (95 \% CI: 0.73,0.98); in obese group, the OR was 0.77 (95\% CI: 0.65,0.91). The interaction between maternal BMI and time of FA supplements was compared to examine why the protective effect was different among different BMI groups. We found that the protective effect of FA supplement in women with normal or underweight had similar values. The effect of FA supplement was different in overweight and obesity group, especially in preconception. Women with a BMI $<24 \mathrm{~kg} / \mathrm{m}^{2}$ (including normal and underweight groups) who took FA supplements from preconception had a lower risk for PTD than in the first trimester (OR: 0.58 vs. 0.65 in the normal weight group, 0.56 vs. 0.60 in the underweight group). Women with a BMI $\geq 24 \mathrm{~kg} / \mathrm{m}^{2}$ (including the overweight and obese groups) who took FA supplements from the first trimester had a lower risk of PTD than at preconception (OR: 0.65 vs. 0.94 in the overweight group, 0.60 vs. 1.15 in the obesity group). Compared with no takers, obese women took FA supplement in preconception had an OR of 1.15 (not statistical significant).

\section{Discussion}

In our research population, the proportion of FA supplementation was as high as $76.8 \%$ and more than $50 \%$ women began to take FA supplements before conception. 
Table 1 Maternal characteristics in study population grouped by preconception body mass index and folic acid supplement

\begin{tabular}{|c|c|c|c|c|c|c|c|c|c|}
\hline & \multicolumn{4}{|c|}{ Preconception body mass index $\left(\mathrm{kg}^{2}\right)$} & \multirow[t]{2}{*}{$P$} & \multicolumn{3}{|c|}{ Folic acid supplement } & \multirow[t]{2}{*}{$P$} \\
\hline & $<18.5$ & $18.5-23.9$ & $24-27.9$ & $\geq 28$ & & Never & 1st trimester & Preconception & \\
\hline \multicolumn{10}{|l|}{ Maternal characteristics } \\
\hline No of subject & 23429 & 129982 & 15880 & 2915 & & 39871 & 41457 & 90878 & \\
\hline \multicolumn{10}{|c|}{ Demographic information (\%) } \\
\hline Maternal age (yr) & 24.96(3.19) & $24.18(3.82)$ & $26.01(4.54)$ & $26.60(4.70)$ & $<0.001$ & $24.85(3.94)$ & $24.77(3.69)$ & 25.13(3.90) & $<0.001$ \\
\hline \multicolumn{10}{|c|}{ Maternal education level } \\
\hline Primary school & 4.72 & 4.96 & 6.78 & 8.03 & $<0.001$ & 5.01 & 4.51 & 5.50 & $<0.001$ \\
\hline Junior school & 60.56 & 67.38 & 71.79 & 72.42 & & 73.50 & 63.63 & 65.57 & \\
\hline High school & 21.82 & 18.81 & 15.29 & 14.68 & & 15.35 & 20.68 & 19.51 & \\
\hline College and above & 12.89 & 8.85 & 6.13 & 4.87 & & 6.14 & 11.18 & 9.42 & \\
\hline \multicolumn{10}{|l|}{ House wife } \\
\hline Yes & 2.60 & 2.21 & 2.15 & 2.06 & 0.002 & 2.11 & 2.41 & 2.24 & 0.013 \\
\hline No & 97.40 & 97.79 & 97.85 & 97.94 & & 97.89 & 97.59 & 97.76 & \\
\hline \multicolumn{10}{|l|}{ Chinese Ethnic group } \\
\hline Chinese Han & 95.36 & 95.02 & 95.41 & 95.64 & 0.015 & 94.98 & 96.47 & 94.55 & $<0.001$ \\
\hline Others & 4.64 & 4.98 & 4.59 & 4.36 & & 5.02 & 3.53 & 5.45 & \\
\hline \multicolumn{10}{|l|}{ Maternal risk factors (\%) } \\
\hline \multicolumn{10}{|c|}{ Previous preterm delivery } \\
\hline No & 99.75 & 99.83 & 99.62 & 99.59 & $<0.001$ & 99.79 & 99.83 & 99.78 & 0.239 \\
\hline Yes & 0.25 & 0.17 & 0.38 & 0.41 & & 0.21 & 0.17 & 0.22 & \\
\hline \multicolumn{10}{|c|}{ Preconception hypertension } \\
\hline No & 98.41 & 97.99 & 95.74 & 90.05 & $<0.001$ & 97.29 & 98.08 & 97.71 & $<0.001$ \\
\hline Yes & 1.59 & 2.01 & 4.26 & 9.95 & & 2.71 & 1.92 & 2.29 & \\
\hline \multicolumn{10}{|l|}{ Anemia } \\
\hline No & 84.54 & 85.99 & 85.21 & 87.38 & $<0.001$ & 83.98 & 83.41 & 87.58 & $<0.001$ \\
\hline Yes & 15.46 & 14.01 & 14.79 & 12.62 & & 16.02 & 16.59 & 12.42 & \\
\hline \multicolumn{10}{|l|}{ Diabetes mellitus } \\
\hline No & 98.34 & 98.77 & 98.05 & 96.84 & $<0.001$ & 98.63 & 98.28 & 98.76 & $<0.001$ \\
\hline Yes & 1.66 & 1.23 & 1.95 & 3.16 & & 1.37 & 1.72 & 1.24 & \\
\hline \multicolumn{10}{|l|}{ Dislike vegetables } \\
\hline No & 99.24 & 99.37 & 99.17 & 99.11 & 0.004 & 99.27 & 99.34 & 99.34 & 0.286 \\
\hline Yes & 0.76 & 0.63 & 0.83 & 0.89 & & 0.73 & 0.66 & 0.66 & \\
\hline \multicolumn{10}{|c|}{ Preconception alcohol use } \\
\hline No & 96.79 & 97.01 & 97.20 & 97.32 & 0.080 & 97.43 & 96.83 & 96.89 & $<0.001$ \\
\hline Yes & 3.21 & 2.99 & 2.80 & 2.68 & & 2.57 & 3.17 & 3.11 & \\
\hline \multicolumn{10}{|c|}{ Preconception Tobacco use } \\
\hline No & 99.63 & 99.70 & 99.57 & 99.31 & $<0.001$ & 99.70 & 99.58 & 99.70 & 0.001 \\
\hline Yes & 0.37 & 0.30 & 0.43 & 0.69 & & 0.30 & 0.42 & 0.30 & \\
\hline \multicolumn{10}{|l|}{ Preterm delivery } \\
\hline No & 94.11 & 94.57 & 94.05 & 93.69 & 0.001 & 92.08 & 94.98 & 95.23 & $<0.001$ \\
\hline Yes & 5.89 & 5.43 & 5.95 & 6.31 & & 7.92 & 5.02 & 4.77 & \\
\hline
\end{tabular}

The reason for the high rate of supplementation in this population was based on a nation-wide free FA supplementation program, which was implemented in rural areas of China since 2009. The Chinese guideline of FA supplements is $0.4 \mathrm{mg} / \mathrm{d}$ from preconception to the end of the first trimester. Women who had rural household 
Table 2 Crude odds ratio (95\% confidence intervals) of preterm delivery by maternal characteristics and single risk factor

\begin{tabular}{|c|c|c|c|c|}
\hline & Number & PTD & & \\
\hline & & $\%$ & COR $(95 \% \mathrm{Cl})$ & $P$ value \\
\hline Maternal characteristics & & & & \\
\hline Maternal age & & & & \\
\hline$\leq 20$ years & 8844 & 5.89 & $1.07(0.98,1.17)$ & 0.14 \\
\hline $21-35$ years & 159640 & 5.53 & 1 & \\
\hline$>35$ years & 3722 & 6.18 & $1.13(0.98,1.29)$ & 0.09 \\
\hline Maternal education level & & & & \\
\hline Primary school and below & 8866 & 4.87 & & \\
\hline Junior school & 115279 & 6.02 & $1.25(1.13,1.38)$ & $<0.01^{*}$ \\
\hline High school & 32418 & 4.42 & $0.90(0.81,1.01)$ & 0.07 \\
\hline College and above & 15643 & 4.88 & $1(0.89,1.13)$ & 0.97 \\
\hline Maternal career & & & & \\
\hline House wife & 3878 & 7.01 & 1 & \\
\hline Others & 168328 & 5.53 & $1.29(1.14,1.46)$ & $<0.01^{*}$ \\
\hline Chinese Ethnic group & & & & \\
\hline Chinese Han & 163786 & 5.67 & 1 & \\
\hline Others & 8420 & 3.46 & $0.60(0.53,0.67)$ & $<0.01^{*}$ \\
\hline Maternal risk factors & & & & \\
\hline Previous preterm delivery & & & & \\
\hline No & 171852 & 5.56 & 1 & \\
\hline Yes & 354 & 6.78 & $1.24(0.82,1.87)$ & 0.32 \\
\hline Preconception BMI & & & & \\
\hline Underweight & 23429 & 5.89 & $1.09(1.03,1.16)$ & $<0.01^{*}$ \\
\hline Normal weight & 129982 & 5.43 & 1 & \\
\hline Overweight & 15880 & 5.95 & $1.10(1.03,1.18)$ & $0.01^{*}$ \\
\hline Obese & 2915 & 6.31 & $1.17(1.01,1.36)$ & $0.04^{*}$ \\
\hline Preconception hypertension & & & & \\
\hline No & 168248 & 5.5 & 1 & \\
\hline Yes & 3958 & 7.98 & $1.49(1.33,1.67)$ & $<0.01^{*}$ \\
\hline Anemia & & & & \\
\hline No & 147657 & 5.42 & 1 & \\
\hline Yes & 24549 & 6.37 & $1.19(1.12,1.25)$ & $<0.01^{*}$ \\
\hline Diabetes mellitus & & & & \\
\hline No & 169819 & 5.55 & 1 & \\
\hline Yes & 2387 & 6.12 & $1.11(0.94,1.31)$ & 0.23 \\
\hline Folic acid supplement & & & & \\
\hline Never & 39871 & 7.92 & 1 & \\
\hline 1st trimester & 41457 & 5.02 & $0.61(0.58,0.65)$ & $<0.01^{*}$ \\
\hline Preconception & 90878 & 4.77 & $0.58(0.56,0.61)$ & $<0.01^{*}$ \\
\hline Dislike vegetables & & & & \\
\hline No & 171047 & 5.55 & 1 & \\
\hline Yes & 1159 & 6.47 & $1.18(0.93,1.49)$ & 0.17 \\
\hline
\end{tabular}

Preconception alcohol use
Table 2 Crude odds ratio (95\% confidence intervals) of preterm delivery by maternal characteristics and single risk factor (Continued)

\begin{tabular}{lllll}
\hline No & 167040 & 5.52 & 1 & \\
Yes & 5166 & 6.78 & $1.24(1.11,1.39)$ & $<0.01^{*}$ \\
Preconception tobacco use & & & & \\
No & 171641 & 5.56 & 1 & \\
Yes & 565 & 6.19 & $0.85(0.58,1.25)$ & 0.42 \\
\hline Note: cOR = crude odds ratio & & & &
\end{tabular}

registration and planned to become pregnant were eligible to obtain FA tablets containing $0.4 \mathrm{mg}$ FA for 6 months at no charge [42].

A negative association was found between FA supplementation and the risk of PTD in our population. FA supplementation showed a strong protective effect on PTD. This protective rate varied from $35 \%$ to $40 \%$ according to different supplementation times. Women who began to take FA supplements in the preconception period had the lowest risk of PTD $(\mathrm{cOR}=0.58$, details in Table 2). Similar results were reported in the USA, where the duration of preconceptional folate supplementation affected the protective effect for PTD. In a metaanalysis, many observational studies suggested a slight reduction in PTD, which was not consistent with the results from randomized, controlled trials [43]. The risk of spontaneous preterm birth decreased with the duration of preconceptional folate supplementation, and taking FA supplements over 1 year could reduce the risk of early spontaneous preterm birth by $50-70 \%$. In contrast, a cohort of Norwegians showed the opposite result, where preconceptional FA supplementation starting more than 8 weeks before conception was associated with an increased risk of PTD (hazard ratio $=1.19$ ) [44]. Another study showed a $20 \%$ lowered risk of PTD was found in the first trimester compared with preconception [33].

In our population, we found that women who were underweight/overweight/obese were at increased risk of PTD in single risk factor analysis (Table 2). Similar results were also reported in the USA and India [29, 45, 46]. Spontaneous preterm birth could be caused by maternal

Table 3 Effect of FA supplement in different BMI group for PTD

\begin{tabular}{lllllllll}
\hline BMl group & \multicolumn{6}{l}{ FA supplement OR $(95 \% \mathrm{Cl})$} \\
\cline { 2 - 8 } & No & Yes & \multicolumn{5}{c}{ 1st trimester } & \multicolumn{3}{c}{ Preconception } \\
\hline Normal & ref & 0.60 & $(0.57,0.63)$ & 0.65 & $(0.61,0.69)$ & 0.58 & $(0.55,0.62)$ \\
Underweight & ref & 0.57 & $(0.51,0.64)$ & 0.60 & $(0.52,0.69)$ & 0.56 & $(0.49,0.63)$ \\
Overweight & ref & 0.85 & $(0.73,0.98)$ & 0.65 & $(0.53,0.79)$ & 0.94 & $(0.80,1.10)$ \\
Obesity & ref & 0.77 & $(0.65,0.91)$ & 0.60 & $(0.37,0.97)$ & 1.15 & $(0.81,1.64)$ \\
\hline
\end{tabular}

Note: Adjusted for maternal education, career, ethnic, hypertension, anemia, alcohol use 
thinness associated with decreased blood volume and fewer vitamins and minerals, which are associated with increased maternal infections. Serum folate levels are lower in obese women than in normal or underweight women [32]. Obese women are more likely to develop pre-eclampsia and diabetes, and indicated preterm births are associated with these disorders [42]. In this study, we could only compare the interaction between FA supplementation and maternal BMI. The direct factor (folate levels) in the population was not compared (without original data). FA supplementation can reduce homocysteine, which causes pre-eclampsia and affects placental function and fetal maturity, eventually leading to PTD. Therefore, analyzing the interaction of FA and BMI for prevention of PTD is important.

An interaction between FA supplements and maternal BMI was found in our population, and the protective effect of FA varied in different BMI groups. Taking FA supplements of $0.4 \mathrm{mg} / \mathrm{d}$ (regardless of when they started) reduced the risk of PTD in all of the BMI groups. The time of taking FA supplement was very important in women with abnormal BMI. In the underweight group, there was very little difference between 1st trimester and preconception. But in overweight and obesity group, the difference was very large. We hypothesize that maternal body size is associated with folate metabolism, which can influence maternal homocysteine levels and affect embryonic development and gestational weeks [23, 47]. Distribution of folate in the body is significantly affected by BMI, and obesity might reduce the amount of folate available to the developing embryo [35, 36]. Obesity-associated metabolic alterations could have an effect on folate use or increase folate requirements $[48,49]$. RBC folate increased incrementally with BMI, while serum folate concentrations were lower in obese groups [50]. We conclude that FA supplementation and maternal obesity can influence homocysteine levels, which might affect placental function and eventually lead to PTD. The distribution of folate might be changed in pregnancy period. We also compared the interaction between the time of FA supplements and maternal BMI. Women with a BMI $<24 \mathrm{~kg} / \mathrm{m}^{2}$ (including the normal and underweight groups) who took FA supplements from preconception had a lower risk for PTD than in the first trimester. Women with a $\mathrm{BMI} \geq 24 \mathrm{~kg} / \mathrm{m}^{2}$ (including the overweight and obese groups) who took FA supplements from the first trimester had a lower risk of PTD than at preconception. Several studies have shown that different supplementation times can change the protective effect of FA $[9,51]$. In a similar study on NTD, the protective of FA was also weaker in the overweight and obesity population than in the normal and underweight population [52]. We suggest that a diverse plan of FA supplementation should be carried out according to women's BMI category. The time and dose of FA supplement for obesity should be taken into account.

\section{Limitations}

The primary limitation in the present study was misclassification of FA supplemental status. We relied on the selfreported use of FA supplements, which could lead to misclassification of FA supplemental status. We compared the proportion of FA supplements in our study with other studies (77\% vs. $68-92 \%[47,53])$. The name and content of the FA supplement was not investigated in the first trimester interview. Therefore, we could not separate FA supplements and multiple vitamin supplements, including FA. Dietary folate was also not estimated in this cohort. We could not calculate the exact folate level. Further research should be carried out to verify the results of this study.

The second limitation of this study was that PTD could not be divided into indicated and spontaneous PTD. Pre-pregnancy obesity is associated with a higher risk of indicated, but not spontaneous, PTD [30]. This study was a retrospective cohort study. We could not analyze the risk of iatrogenic PTD because this type of PTD was not classified in the follow-up records. Detailed data should be collected to estimate the protective effect of FA between indicated PTD and spontaneous PTD in the future.

Because of the uncertainty of natural conception, we selected women who became pregnant in the following 6 months after the preconception medical examination as our research population. All statistical research was carried out in this population, which could also have reduced the effect of a change in maternal medical status on the results. Reported supplementation of FA for 1 year prior to conception has been linked with a decreased risk of preterm birth [54]. In our cohort, we did not test the protective effect of FA from 1 year before conception in our population. Because our study design only included 6 months of FA supplements in the pregnant population, the results may not apply to the whole population.

\section{Conclusions}

In our study, FA supplements reduced the risk of PTD, while abnormal BMI raised the risk of PTD, although higher BMI categories did not have this higher risk once adjusted analysis was conducted. The protective effect of FA supplementation for PTD is reduced in women whose BMI was equal or greater than $24 \mathrm{~kg} / \mathrm{m}^{2}$. To get better protection of FA supplementation, women with $\mathrm{BMI}<24 \mathrm{~kg} / \mathrm{m}^{2}$ should begin to use in preconception, while women with $B M I \geq 24 \mathrm{~kg} / \mathrm{m}^{2}$ should begin to use after conception. 


\section{Abbreviations}

FA: Folic acid; BMI: Body mass index; PTD: Preterm delivery; COR: Crude odds ratio; aOR: Adjusted odds ratio; Cls: Confidence intervals.

\section{Competing interests}

The authors declare that they have no competing interests.

\section{Authors' contributions}

YY Wang: Study design and paper writing. ZF Cao: Statistical anlysis. ZQ Peng: Data collection. XN Xin: Data collection. Y Zhang: Data collection.Y Yang: Paper review. Y He: Paper review. JH Xu: Paper review. X Ma: Study design. All authors read and approved the final manuscript.

\section{Acknowledgements}

We thank all the participants in this research and all the medical staffs in the 100 counties for their hard work in NFPC.

\section{Financial support}

This study was supported by the "Five-twelfth" National Science and Technology Support Program (No.2012BAI41B08, No.2013BAl12B01) and the National Natural Science Foundation(No.41401469),People's Republic of China.

\section{Received: 28 April 2015 Accepted: 2 December 2015}

\section{Published online: 15 December 2015}

\section{References}

1. Gravett MG, Rubens CE. Global Alliance to Prevent Prematurity and Stillbirth Technical Team: A framework for strategic investments in research to reduce the global burden of preterm birth. Am J Obstet Gynecol. 2012;207: 368-73.

2. Liang J, Mao M, Dai L, Li X, Miao L, Li Q, et al. Neonatal mortality due to preterm birth at 28-36 weeks' gestation in China, 2003-2008. Paediatr Perinat Epidemiol. 2011;25:593-600.

3. Werler MM, Shapiro S, Mitchell AA. Mitchell, Periconceptional folic acid exposure and risk of occurrent neural tube defects. Jama. 1993;269:1257-61.

4. Shaw GM, Schaffer D, Velie EM, Morland K, Harris JA. Periconceptional vitamin use, dietary folate, and the occurrence of neural tube defects. Epidemiology. 1995;6:219-26.

5. Rozendaal AM, van Essen AJ, te Meerman GJ, Bakker MK, van der Biezen JJ, Goorhuis-Brouwer SM, et al. Periconceptional folic acid associated with an increased risk of oral clefts relative to non-folate related malformations in the Northern Netherlands: a population based case-control study. Eur J Epidemiol. 2013;28:875-87.

6. Li Z, Ye R, Zhang L, Li H, Liu J, Ren A. Periconceptional folic acid supplementation and the risk of preterm births in China: a large prospective cohort study. Int J Epidemiol. 2014;43:1132-9.

7. Czeizel AE, Puhó EH, Langmar Z, Acs N, Bánhidy F. Possible association of folic acid supplementation during pregnancy with reduction of preterm birth: a population-based study. Eur J Obstet Gynecol Reprod Biol. 2010;148:135-40.

8. Naimi Al, Auger N. Population-wide folic acid fortification and preterm birth: testing the folate depletion hypothesis. Am J Public Health. 2015;105(4): 793-5.

9. Papadopoulou E, Stratakis N, Roumeliotaki T, Sarri K, Merlo DF, Kogevinas M, et al. The effect of high doses of folic acid and iron supplementation in early-to-mid pregnancy on prematurity and fetal growth retardation: the mother-child cohort study in Crete, Greece (Rhea study). Eur J Nutr. 2013;52:327-36.

10. Dunlop AL, Taylor RN, Tangpricha V, Fortunato S, Menon R. Maternal micronutrient status and preterm versus term birth for black and white US women. Reprod Sci. 2012;19:939-48.

11. Yamada T, Morikawa M, Yamada T, Kishi R, Sengoku K, Endo T, et al. Firsttrimester serum folate levels and subsequent risk of abortion and preterm birth among Japanese women with singleton pregnancies. Arch Gynecol Obstet. 2013;287:9-14.

12. Naimi Al, Auger N. Population-wide folic acid fortification and preterm birth: testing the folate depletion hypothesis. Am J Public Health. 2015:105:793-5.

13. Lassi ZS, Salam RA, Haider BA, Bhutta ZA. Folic acid supplementation during pregnancy for maternal health and pregnancy outcomes. Cochrane Database Syst Rev. 2013;3:CD006896.
14. Bakker R, Timmermans S, Steegers EA, Hofman A, Jaddoe WW. Folic acid supplements modify the adverse effects of maternal smoking on fetal growth and neonatal complications. J Nutr. 2011;141:2172-9.

15. Shah R, Mullany LC, Darmstadt GL, Mannan I, Rahman SM, Talukder RR, et al. Incidence and risk factors of preterm birth in a rural Bangladeshi cohort. BMC Pediatr. 2014;14:112.

16. Chen LW, Lim AL, Colega M, Tint MT, Aris IM, Tan CS, et al. Maternal folate status, but not that of vitamins B-12 or B-6, is associated with gestational age and preterm birth risk in a multiethnic Asian population. J Nutr. 2015;145:113-20.

17. Scholl TO, Hediger ML, Schall Jl, Khoo CS, Fischer RL. Dietary and serum folate: their influence on the outcome of pregnancy. Am J Clin Nutr. 1996;63:520-5.

18. Siega-Riz AM, Savitz DA, Zeisel SH, Thorp JM, Herring A. Second trimester folate status and preterm birth. Am J Obstet Gynecol. 2004;191:1851-7.

19. Zhao M, Chen YH, Dong XT, Zhou J, Chen X, Wang H, et al. Xu DX Folic acid protects against lipopolysaccharide-induced preterm delivery and intrauterine growth restriction through its anti-inflammatory effect in mice. PLoS One. 2013:8:e82713.

20. Kim H, Hwang JY, Ha EH, Park H, Ha M, Lee SJ, et al. Association of maternal folate nutrition and serum C-reactive protein concentrations with gestational age at delivery. Eur J Clin Nutr. 2011;65:350-6.

21. Simhan HN, Himes KP, Venkataramanan R, Bodnar LM. Maternal serum folate species in early pregnancy and lower genital tract inflammatory milieu. Am J Obstet Gynecol. 2011;205(61):e1-7.

22. Dhobale M, Chavan P, Kulkarni A, Mehendale S, Pisal H, Joshi S. Reduced folate, increased vitamin $\mathrm{B}(12)$ and homocysteine concentrations in women delivering preterm. Ann Nutr Metab. 2012;61:7-14.

23. Kim MW, Hong SC, Choi JS, Han JY, Oh MJ, Kim HJ, et al. folate and pregnancy outcomes. J Obstet Gynaecol. 2012;32:520-4.

24. Papachatzi E, Dimitriou G, Dimitropoulos K, Vantarakis A. Pre-pregnancy obesity: maternal, neonatal and childhood outcomes. J Neonatal Perinatal Med. 2013;6:203-16.

25. Lynch AM, Hart JE, Agwu OC, Fisher BM, West NA, Gibbs RS. Association of extremes of prepregnancy BMI with the clinical presentations of preterm birth. Am J Obstet Gynecol. 2014;210(428):e1-9.

26. Dean SV, Lassi ZS, Imam AM, Bhutta ZA. Preconception care: nutritional risks and interventions. Reprod Health. 2014:11 Suppl 3:S3.

27. Fujiwara K, Aoki S, Kurasawa K, Okuda M, Takahashi T, Hirahara F. Associations of maternal pre-pregnancy underweight with small-for-gestational-age and spontaneous preterm birth, and optimal gestational weight gain in Japanese women. J Obstet Gynaecol Res. 2014;40:988-94.

28. Shin D, Song WO. Prepregnancy body mass index is an independent risk factor for gestational hypertension, gestational diabetes, preterm labor, and small- and large-for-gestational-age infants. J Matern Fetal Neonatal Med. 2015;28:1679-86.

29. Parker MG, Ouyang F, Pearson C, Gillman MW, Belfort MB, Hong X, et al. Prepregnancy body mass index and risk of preterm birth: association heterogeneity by preterm subgroups. BMC Pregnancy Childbirth. 2014;14:153.

30. Shaw GM, Carmichael SL, Yang W. Siega-Riz AM; National Birth Defects Prevention Study: Periconceptional intake of folic acid and food folate and risks of preterm delivery. Am J Perinatol. 2011;28:747-52.

31. Tinker SC, Hamner HC, Berry RJ, Bailey LB, Pfeiffer CM. Does obesity modify the association of supplemental folic acid with folate status among nonpregnant women of childbearing age in the United States? Birth Defects Res A Clin Mol Teratol. 2012;94:749-55.

32. Mojtabai R. Body mass index and serum folate in childbearing age women. Eur J Epidemiol. 2004;19(11):1029-36.

33. da Silva VR, Hausman DB, Kauwell GP, Sokolow A, Tackett RL, Rathbun SL, et al. Obesity affects short-term folate pharmacokinetics in women of childbearing age. Int J Obes (Lond). 2013;37:1608-10.

34. Kim H, Hwang JY, Kim KN, Ha EH, Park H, Ha M, et al. Relationship between body-mass index and serum folate concentrations in pregnant women. Eur J Clin Nutr. 2012;66:136-8.

35. Stern SJ, Matok I, Kapur B, Koren G. Dosage requirements for periconceptional folic acid supplementation: accounting for BMI and lean body weight. J Obstet Gynaecol Can. 2012;34:374-8.

36. Wilson RD, Johnson JA, Wyatt $P$, Allen V, Gagnon A, Langlois $S$, et al. Genetics Committee of the Society of Obstetricians and Gynaecologists of Canada and The Motherrisk Program: Pre-conceptional vitamin/folic acid supplementation 2007: the use of folic acid in combination with a multivitamin supplement for the prevention of neural tube defects and other congenital anomalies. J Obstet Gynaecol Can. 2007;29:1003-26. 
37. National Bureau of Statistics of China. China Statistical Yearbook 2011. http://www.stats.gov.cn/tjsj/ndsj/2011/indexeh.htm. Accessed date 2011.

38. Goldenberg RL, Culhane JF, lams JD, Romero R. Epidemiology and causes of preterm birth. Lancet. 2008;371:75-84.

39. National Health and Family Planning Commission of the People's Republic of China. Criteria of weight for adults. http://www.moh.gov.cn/ewebeditor/ uploadfile/2013/08/20130808135715967.pdf. Accessed date 2013.

40. Chen C, Lu FC, Department of Disease Control Ministry of Health, PR China. The guidelines for prevention and control of overweight and obesity in Chinese adults. Biomed Environ Sci. 2004;17(Suppl):1-36.

41. Rothman K, Greenland S, Lash T, editors. Modern Epidemiology. Philadelphia: Lippincott Williams \& Wilkins; 2008.

42. Liu J, Jin L, Meng Q, Gao L, Zhang L, Li Z, et al. Changes in folic acid supplementation behaviour among women of reproductive age after the implementation of a massive supplementation programme in China. Public Health Nutr. 2015;18:582-8.

43. Mantovani E, Filippini F, Bortolus R, Franchi M. Folic acid supplementation and preterm birth: results from observational studies. Biomed Res Int. 2014 2014:481914.

44. Sengpiel V, Bacelis J, Myhre R, Myking S, Devold Pay AS, Haugen M, et al. Folic acid supplementation, dietary folate intake during pregnancy and risk for spontaneous preterm delivery: a prospective observational cohort study. BMC Pregnancy Childbirth. 2014;14:375.

45. Johnson TS, Rottier KJ, Luellwitz A, Kirby RS. Maternal prepregnancy body mass index and delivery of a preterm infant in Missouri 1998-2000. Public Health Nurs. 2009;26:3-13.

46. Mandal D, Manda S, Rakshi A, Dey RP, Biswas SC, Banerjee A. Maternal obesity and pregnancy outcome: a prospective analysis. J Assoc Physicians India. 2011;59:486-9.

47. Sukla KK, Tiwari PK, Kumar A, Raman R. Low birthweight (LBW) and neonata hyperbilirubinemia (NNH) in an Indian cohort: association of homocysteine, its metabolic pathway genes and micronutrients as risk factors. PLoS One. 2013;8:e71587.

48. Goldberg BB, Alvarado S, Chavez C, Chen BH, Dick LM, Felix RJ, et al. Teratogen Information Service: Prevalence of periconceptional folic acid use and perceived barriers to the postgestation continuance of supplemental folic acid: survey results from a Teratogen Information Service. Birth Defects Res A Clin Mol Teratol. 2006;76:193-9.

49. Watkins ML, Scanlon KS, Mulinare J, Khoury MJ. Is maternal obesity a risk factor for anencephaly and spina bifida? Epidemiology. 1996;7:507-12.

50. Bird JK, Ronnenberg AG, Choi SW, Du F, Mason JB, Liu Z. Obesity is associated with increased red blood cell folate despite lower dietary intakes and serum concentrations. J Nutr. 2015;145(1):79-86.

51. Bergen NE, Jaddoe WW, Timmermans S, Hofman A, Lindemans J, Russcher H, et al. Homocysteine and folate concentrations in early pregnancy and the risk of adverse pregnancy outcomes: the Generation R Study. BJOG. 2012;119:739-51.

52. Wang M, Wang ZP, Gao LJ, Gong R, Sun XH, Zhao ZT. Maternal body mass index and the association between folic acid supplements and neural tube defects. Acta Paediatr. 2013;102:908-13.

53. Xing XY, Tao FB, Hao JH, Huang $K$, Huang ZH, Zhu XM, et al. Periconceptional folic acid supplementation among women attending antenatal clinic in Anhui, China: data from a population-based cohort study. Midwifery. 2012;28:291-7.

54. Bukowski R, Malone FD, Porter FT, Nyberg DA, Comstock CH, Hankins GD, et al. Preconceptional folate supplementation and the risk of spontaneous preterm birth: a cohort study. PLoS Med. 2009;6:e1000061.

\section{Submit your next manuscript to BioMed Central and we will help you at every step:}

- We accept pre-submission inquiries

- Our selector tool helps you to find the most relevant journal

- We provide round the clock customer support

- Convenient online submission

- Thorough peer review

- Inclusion in PubMed and all major indexing services

- Maximum visibility for your research

Submit your manuscript at www biomedcentral com/submit 